
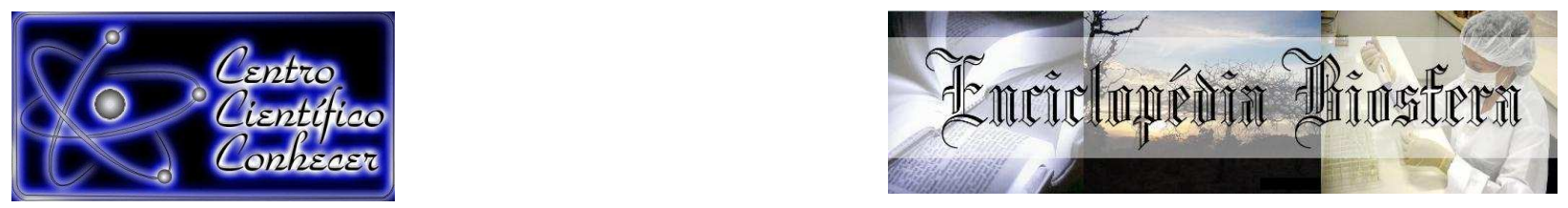

\title{
MEDIDAS DE BAIXO IMPACTO PARA O CONTROLE DE ALAGAMENTOS E INUNDAÇÕES APLICADAS NA BACIA HIDROGRÁFICA DO RIO BELÉM EM CURITIBA, PARANÁ
}

Alessandro Bertolino', Carlos Mello Garcias ${ }^{2}$, Edilberto Nunes de Moura ${ }^{3}$, Stéphanie Louise Inácio Castro ${ }^{4}$

1 Professor Mestre do Curso de Engenharia Ambiental da Pontifícia Universidade

Católica do Paraná (alessandro.bertolino@gmail.com) Curitiba - Brasil

2 Professor Doutor do Programa de Pós-Graduação em Gestão Urbana da Pontifícia Universidade Católica do Paraná

3 Professor Doutor do Programa de Pós-Graduação em Gestão Urbana da Pontifícia Universidade Católica do Paraná

4 Aluna de Mestrado do Programa de Pós-Graduação em Gestão Urbana da Pontifícia Universidade Católica do Paraná

Recebido em: 08/04/2016 - Aprovado em: 30/05/2016 - Publicado em: 20/06/2016 DOI: 10.18677/Enciclopedia_Biosfera_2016_066

\begin{abstract}
RESUMO
O processo de urbanização provocou modificações no ambiente, alterando as estruturas físicas naturais. A interferência humana atinge o ciclo da água, pois o processo de armazenamento e transferência deste elemento no solo é modificado com a impermeabilização da superfície. Uma técnica que pode ser implantada é a do desenvolvimento de baixo impacto, a qual atua no gerenciamento e controle do escoamento das águas pluviais, adotando métodos de armazenamento, infiltração, evaporação e amortecimento do escoamento superficial. O objetivo desse estudo foi verificar a possibilidade de implantação de medidas de baixo impacto para o controle de inundações e alagamentos na bacia hidrográfica do Rio Belém, em Curitiba, Paraná. As condicionantes de locação de medidas de baixo impacto foram estudadas, e, em seguida, utilizando-se banco de dados da região e o software ArcGIS 10.2, criou-se um mapa para cada condicionante. Posteriormente, foi realizado o cruzamento de informações entre os mapas para se chegar ao mapa final, com as aptidões locais para receber tais medidas. Verificou-se que apenas $15 \%$ da área total da bacia encontram-se livres para a aplicação das medidas. Destes, 34\% são regiões inaptas, 47\% apresentam média aptidão e 19\% das áreas livres são favoráveis à implantação. Em nível de subbacias, a implantação do método mostra-se viável, embora sejam necessárias obras complementares na maioria das áreas.
\end{abstract}

PALAVRAS-CHAVE: Bacia Hidrográfica do Rio Belém. Desenvolvimento de Baixo Impacto. Inundações e Alagamentos. 


\title{
LOW IMPACT DEVELOPMENT FOR CONTROL FLOODS IN THE RIVER BASIN BELÉM, CURITIBA, PARANÁ
}

\begin{abstract}
The process of urbanization caused changes in the natural environment, altering their physical structures. The human interference affects the water cycle, because the storage process and transfer it in soil is modified with surface sealing. One technique that has recently been implemented is the low impact development, which operates in the management and control of storm water runoff, adopting methods of storage, infiltration, evaporation and runoff cushioning. The objective of this paper is to check the viability of implementing of low impact measures for flood control that could be applied in the urban environment of the River Basin Belém, Curitiba, Paraná. The conditions for implementing low impact measures were studied and then by ArcGIS 10.2 software and a database, a map was created for each condition. Finally, was done the crossing data between maps to get the final map, with the ability to receive these local measures. It was verified that only $15 \%$ of the total area of the basin are free to implement the measures. Of these, 34\% are unfit regions, $47 \%$ have average aptitude and $19 \%$ of the free areas are favorable to deployment. It was observed that at the level of sub-basins, the implementation of low impact development is practicable, although additional works is needed in most areas.
\end{abstract}

KEYWORDS: River Basin Belem. Low Impact Development. Floods.

\section{INTRODUÇÃO}

As regiões urbanas são mais favoráveis a inundações e alagamentos, pois o solo dessas regiões é impedido, pelo asfalto e diversos tipos de pavimentações, de absorver a água e até pela insuficiência de vegetação que naturalmente contribui para a absorção da água. A pavimentação de vias esteve e ainda está presente nas ideias de progresso. Promover facilidades de tráfego de pessoas e veículos faz com que $o$ asfalto predomine em áreas onde antes a infiltração da água se fazia de maneira fácil (GÓIS \& MENDES, 2013).

Problemas como esses podem e devem ser amenizados por meio do planejamento urbano, buscando-se soluções para reduzir os eventos e os danos causados pelas inundações. Dentre as diferentes formas de controle para a proteção contra inundações e os riscos que as mesmas podem trazer, existem meios estruturais e não estruturais. As medidas estruturais são fundamentalmente projetadas e construídas unicamente para o controle de cheias. As medidas não estruturais têm como objetivo a melhor coexistência da população com as inundações e fundamenta-se em princípios que disciplinam o uso do solo, a tipologia das construções transitáveis, seguros e sistemas de alerta (TUCCI, 2003).

As práticas convencionais de drenagem baseiam-se no transporte das águas pluviais para mais longe, o mais rápido possível. Porém quanto mais as águas das chuvas nas cidades são retardadas para chegar ao curso d'água, menor o risco de inundações. Uma prática para que ocorra esse retardamento é a retenção no início do escoamento, nos próprios lotes, por exemplo, ou pela infiltração ou armazenamento quando se trata de macrodrenagem. Essas medidas visam evitar a transferência dos impactos causados pelas cheias em áreas à jusante. Uma técnica que recentemente vem sendo implantada é a do desenvolvimento de baixo impacto (MIGUEZ et al., 2015), a qual atua no gerenciamento e controle do escoamento das águas pluviais, adotando métodos de armazenamento, infiltração, evaporação e amortecimento do escoamento superficial. Tais técnicas são consideradas medidas 
estruturais, porém não convencionais. Cidades americanas, como Seattle e Portland, são exemplos de locais que já aderiram a esses sistemas. Algumas técnicas empregadas podem ser citadas a biorretenção, trincheiras de infiltração, aproveitamento de água da chuva, paisagismo com água da chuva, pavimentos permeáveis e telhados verdes, entre outros (TASSI et al., 2014).

As medidas de baixo impacto abrangem a gestão e o controle do escoamento das águas pluviais na tentativa de reconstituir as condições hidrológicas de prédesenvolvimento do local, usando práticas de armazenamento, infiltração, evaporação e amortecimento do escoamento superficial. Para Melo et al. (2014), essas técnicas assinalam uma "solução em potencial para o desenvolvimento de cidades hidrologicamente sustentáveis, minimizando os efeitos inoportunos de um processo de urbanização não planejado e contribuindo para a restauração de ecossistemas urbanos."

Para PENNIMAN et al. (2013), as medidas de baixo impacto podem ser efetivas no planejamento do escoamento das águas pluviais no meio urbano. Neste estudo, as técnicas contempladas utilizam a infiltração como base de funcionamento. Para implantar essas técnicas existem requisitos técnicos, chamados de condicionantes locais. Esses requisitos envolvem o espaço requerido, a permeabilidade do solo, o nível do lençol freático e a declividade. Portanto, o objetivo desse estudo foi verificar a possibilidade de implantação de medidas de baixo impacto para o controle de inundações e alagamentos na bacia hidrográfica do Rio Belém, em Curitiba, Paraná.

\section{MATERIAL E MÉTODOS}

Para realização deste trabalho as condicionantes para os locais de implantação foram mapeadas para obter a viabilidade local da Bacia Hidrográfica do Rio Belém, localizada na cidade de Curitiba, Paraná, em receber as medidas de baixo impacto para o controle de inundações e alagamentos. Desta forma, instrumentos de geoprocessamento foram utilizados para analisar a viabilidade de implantação de medidas de baixo impacto para o controle de inundações e alagamentos no meio urbano da Bacia Hidrográfica do Rio Belém.

O Rio Belém nasce ao norte da cidade e tem sua foz na região sul da cidade de Curitiba, descarregando suas águas no Rio Iguaçu. Percorre uma extensão de 28 $\mathrm{km}$, atravessando Curitiba, e sua bacia abriga cerca de $40 \%$ da população, além de importantes símbolos que representam a identidade da capital paranaense sob as diversas visões antrópicas. No âmbito político, incluem-se nela as sedes dos poderes municipal e estadual; para a abordagem turística, belos parques, como o São Lourenço, o Bosque do Papa, o Passeio Público, a Ópera de Arame e o Jardim Botânico; como marcos históricos e culturais, o Largo da Ordem, o Teatro Guaíra e o Museu Oscar Niemeyer; num contexto econômico, importantes bairros comerciais, destacando-se o Centro, o Centro Cívico e o Batel. A Figura 1 apresenta a localização da bacia hidrográfica do rio Belém em Curitiba. 

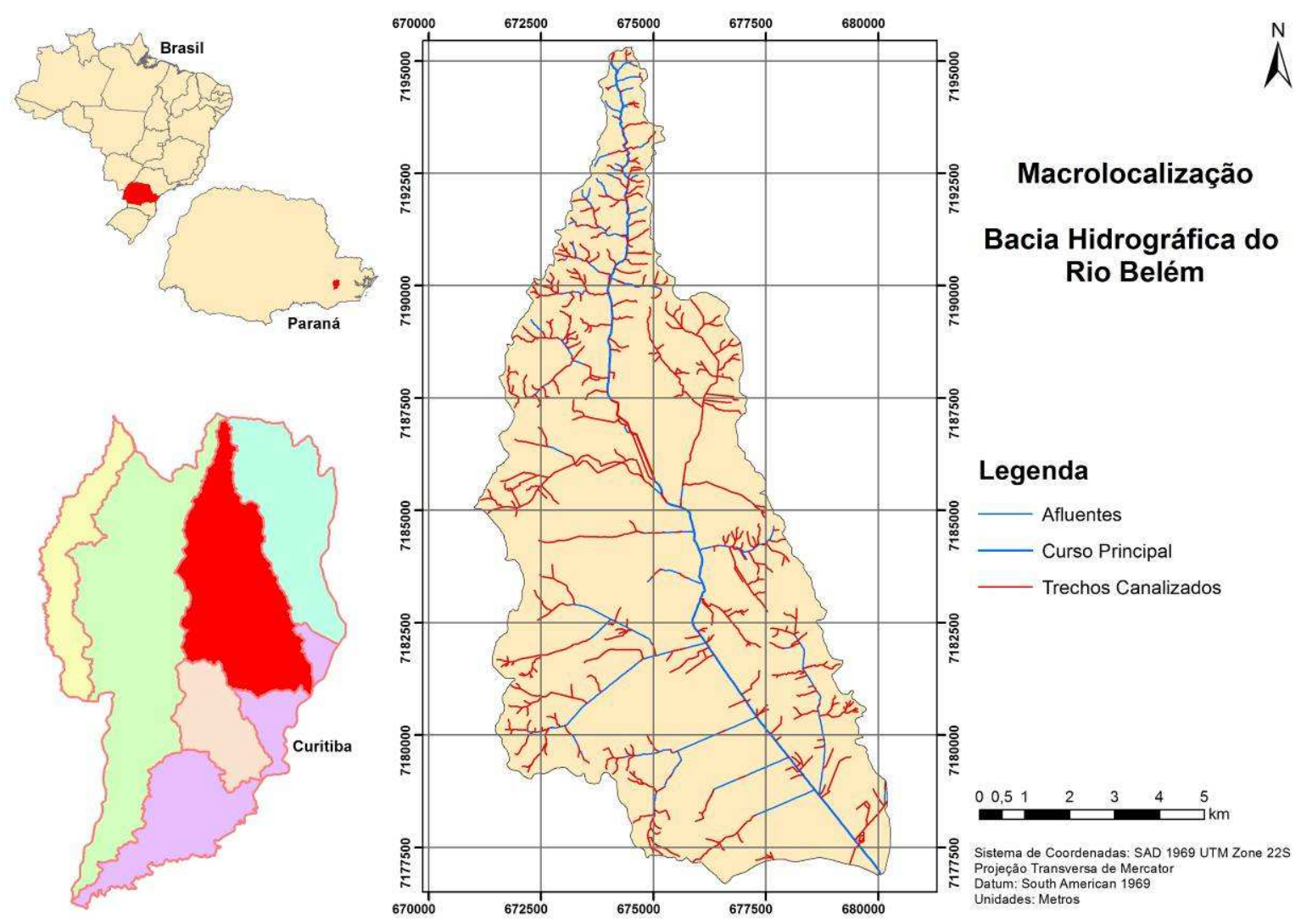

FIGURA 1 - Macrolocalização Da Bacia Hidrográfica do Rio Belém.

Fonte: Adaptado de IPPUC, 2013.

Para realização do presente estudo, as condicionantes para os locais de implantação das medidas foram mapeadas para se obter a aptidão local da Bacia Hidrográfica do Rio Belém para receber as medidas de baixo impacto para o controle de inundações e alagamentos. Partiu-se do pressuposto que cada tipo de medida, seja estrutural ou não, possui condicionante, isto é, fatores técnicos, políticos ou econômicos que precisam ser levados em consideração no projeto executivo. A partir disso, tomou-se como base o quadro com as restrições para que a técnica pudesse ser aplicada, conforme a síntese no Quadro 1 e no Quadro 2. Dentre as medidas apresentadas, o barril de chuva e a cisterna não dependem de fatores locais para implantação, mas sim de projeto no local da obra, portanto não serão considerados neste estudo. Das condicionantes, as que puderam ser mapeadas, pela existência ou possibilidade de acesso aos dados, foram espaço requerido, solos, declividades e profundidade do lençol freático. As demais condicionantes devem ser consideradas no projeto de implantação, porém não foram consideradas nesta pesquisa.

QUADRO 1 - Tipos de Medidas de Baixo Impacto

\begin{tabular}{|l|}
\multicolumn{1}{|c|}{ MEDIDAS DE BAIXO IMPACTO } \\
\hline Bioretenção \\
\hline Poço seco \\
\hline Faixa Filtrante/Proteção \\
\hline Valas (Gramadas, Infiltração, molhadas) \\
\hline Trincheira de Infiltração \\
\hline Barris de chuva \\
\hline Cisterna \\
\hline
\end{tabular}

Nota: Os itens em negrito foram os utilizados neste estudo. 
QUADRO 2 - Condicionantes das Medidas de Baixo Impacto

\begin{tabular}{|l|}
\hline \multicolumn{1}{|c|}{ CONDICIONANTES } \\
\hline Espaço requerido \\
\hline Solos \\
\hline Declividades \\
\hline Profundidade do lençol freático \\
\hline Proximidade a fundações de edificações \\
\hline Profundidade máxima \\
\hline Manutenção \\
\hline
\end{tabular}

Nota: Os itens em negrito foram os utilizados neste estudo.

Assim, foi proposto um mapeamento que relacione as características presentes em determinada área, no caso, a Bacia Hidrográfica do Rio Belém, com as características ideais ou favoráveis à implantação. Cada requisito para implantação da técnica foi avaliado e posteriormente foram reunidas bases cartográficas que pudessem ser utilizadas em uma plataforma de Sistema de Informação Geográfica, no caso o software ArcGIS 10.2, para que cada requisito pudesse ser mapeado. Os mapas foram gerados com dados disponibilizados pelos Departamentos de Geoprocessamento do Instituto de Pesquisa e Planejamento Urbano de Curitiba (IPPUC) e do Instituto das Águas do Paraná, com escala aproximada de 1/10000, exceto os dados pedológicos, em escala 1/50000. Desta forma obtiveram-se dados vetoriais para os requisitos: espaço requerido, solos, declividades e lençol freático.

Para uma análise mais apurada, ponto a ponto da bacia, os dados em base vetorial foram transformados em formato matricial. Optou-se pela padronização de todos os grids formados, com tamanho de pixel de dois metros. Para a análise foi definido um sistema de pontuação, no qual os valores mais altos representam maior aptidão em receber as técnicas e um valor nulo representa a inaptidão do local. Após a obtenção dos dados e a confecção dos mapas em formato matricial de cada parâmetro necessário para a implantação das medidas, foi utilizada a ferramenta "Raster Calculator" do software utilizado para a confecção do mapa final. Assim os mapas foram multiplicados, criando-se um mapa final de aptidão para o recebimento da tecnologia estudada.

A multiplicação foi escolhida pelo fato de alguns requisitos técnicos da aplicação das medidas de baixo impacto serem restritivos. Na região em que o requisito não atende a condicionante local, este não é apto para receber as medidas, ou seja, dados com valor zero (não atendem aos requisitos pedidos) na multiplicação anulam o resultado, satisfazendo a condição de não aptidão do local. Deste modo, as células de cada mapa foram multiplicadas entre si:

'Áreas livres $x$ Permeabilidade do solo $x$ Declividades $x$ Profundidade do Lençol Freático = Aptidão Local'

Para a composição do mapa de espaço requerido utilizaram-se bases cartográficas referentes à localização de áreas livres dentro da bacia hidrográfica. Nessa primeira composição, foi utilizado o mapa com a localização de parques, bosques, praças e jardinetes, além de um mapa com as áreas verdes da região em estudo. Porém, esse mapa de áreas verdes foi editado para que áreas que representassem árvores e suas copas ao longo de calçadas, por exemplo, não fossem usadas, com o intuito de diminuir os erros de escolha de local. 
Após a composição vetorial dessas áreas livres, através de união de bases, gerou-se o mapa matricial para que cada pixel assumisse uma identidade referente à sua área livre (disponível ou não). Posteriormente cada pixel foi reclassificado visto a possibilidade em receber as medidas de baixo impacto. Desse modo, para as áreas livres o valor de classificação foi 1 (um), pois todas os locais possuíam área superior ao maior valor mínimo requerido. Para os locais sem áreas livres, ou seja, sem aptidão para receber as medidas, foi atribuído valor zero.

Todas as áreas em verde possuem valor de célula igual a 1 (um). Áreas em branco, sem a possibilidade de receber medidas, possuem valor zero. Para criar a permeabilidade do solo, utilizou-se o mapa pedológico da região. Assim, o mapa de solos em formato vetorial também foi transformado em um grid de células e cada célula foi reclassificada com valores de classificação de permeabilidade, variando entre baixo, médio e alto poder de infiltração.

Assim, deu-se a reclassificação conforme o Quadro 3:

QUADRO 3 - Reclassificação para as características dos solos

\begin{tabular}{|l|c|c|}
\hline \multicolumn{1}{|c|}{ TIPO DE SOLO } & PODER DE INFILTRAÇÃO & VALOR ATRIBUÍDO \\
\hline Solos Hidromórficos & Baixo & 0 \\
\hline Argissolo e Cambissolo & Médio & 1 \\
\hline Latossolo & Alto & 2 \\
\hline
\end{tabular}

O valor zero demonstra impossibilidade em receber as medidas consideradas. $\mathrm{O}$ valor 1 (um), representa possibilidade, porém com maior dificuldade. E valor 2 (dois) demonstra aptidão em receber a técnica pelo fator de permeabilidade do solo.

Para a determinação da declividade da bacia, o mapa altimétrico da bacia hidrográfica, cotado de metro em metro, foi inserido no software ArcGis 10.2, onde foi criado um modelo de interpolação TIN (Triangular Irregular Network). Uma rede irregular triangular (TIN) é uma estrutura de dados digital utilizada em um sistema de informação geográfica para representar uma superfície. Essa rede é composta irregularmente de nós e linhas distribuídos com coordenadas tridimensionais $(\mathrm{X}, \mathrm{Y}$ e Z) que são organizados em uma rede de triângulos que não se sobrepõem.

A partir do TIN, gerou-se um arquivo matricial, com o atributo de elevação, através do comando 'convert to Grid'. Com base no grid, foi criado o Modelo Digital do Terreno (MDT). Adotou-se como tamanho de célula dois metros. A partir desse modelo digital do terreno criado, com a ferramenta 'Slope', criou-se o mapa de declividade.

Como os requisitos de declividade do local não são considerados fatores limitantes pela metodologia estudada, todo o mapa foi reclassificado com o valor 1 (um), ou seja, toda a região da bacia é apta, pela declividade, para o recebimento das medidas. O mapa de profundidade de lençol freático foi gerado a partir de 410 pontos cotados com a profundidade do lençol freático da cidade de Curitiba. A partir desses pontos, foi realizada uma interpolação IDW (Inverso do Quadrado da Distância) entre os pontos, a qual gerou um mapa matricial da área de Curitiba com os valores de profundidade para cada pixel. A partir deste mapa gerado, recortou-se o mapa referente a bacia hidrográfica do Rio Belém.

Posteriormente cada pixel foi reclassificado de acordo com a possibilidade de receber as medidas de baixo impacto. Desse modo, para a profundidade do lençol freático superior a $0,6 \mathrm{~m}$ o valor de classificação foi 1 (um). Para os locais onde a 
profundidade do lençol freático é inferior a $0,6 \mathrm{~m}$, ou seja, sem aptidão para receber as medidas, foi atribuído valor zero.

A Figura 2 apresenta um fluxograma com o resumo das etapas desenvolvidas na metodologia.

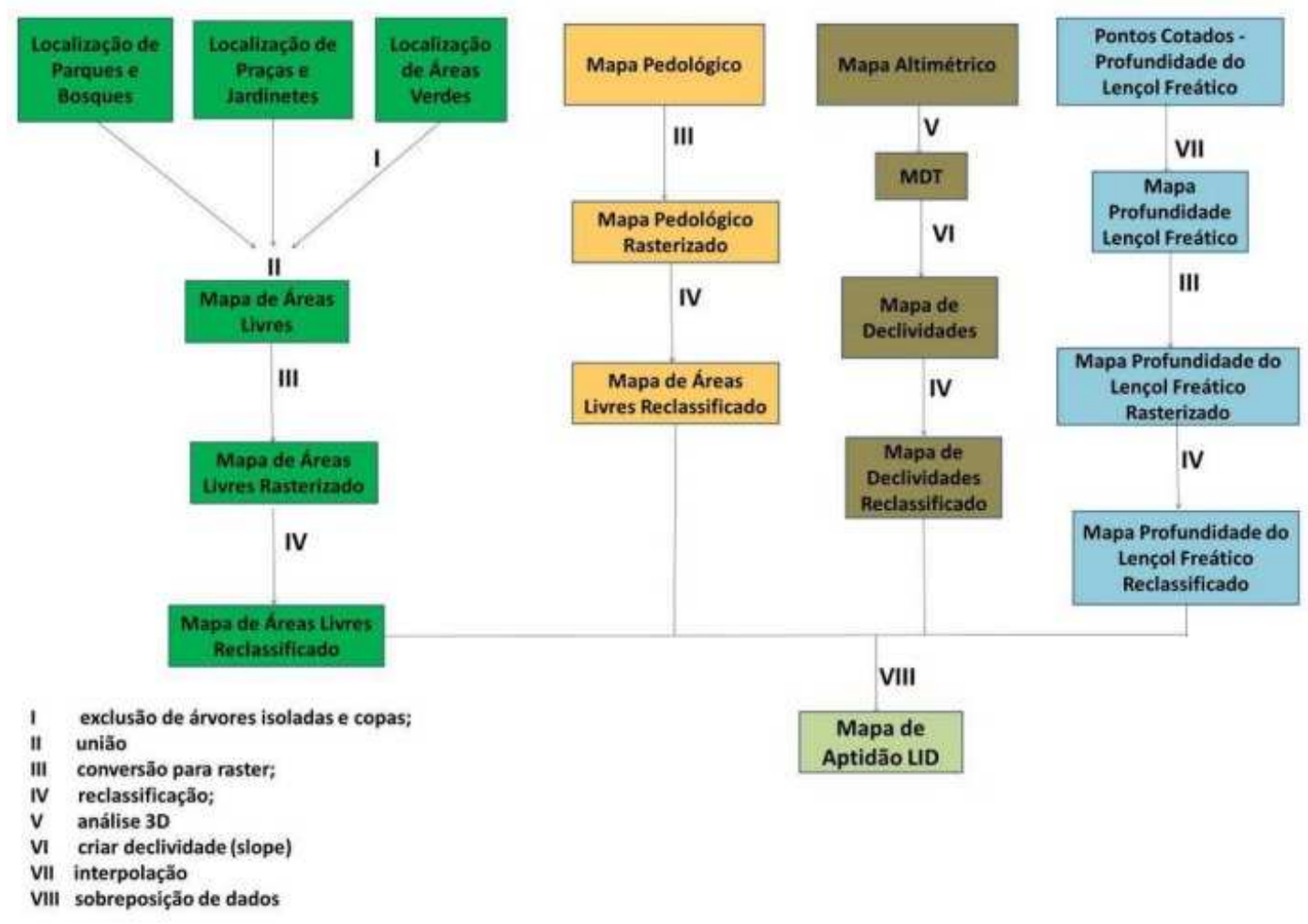

FIGURA 2 - Fluxograma de aplicação da metodologia desenvolvida.

Fonte: autores, 2016.

\section{RESULTADOS E DISCUSSÃO}

Tomando o método de criação dos mapas descrito no capítulo anterior, foram criados os mapas referentes a cada condicionante descrita. Primeiramente foram unidos os dados referentes a áreas verdes, bosques, praças, parques e jardinetes. A união desses dados gerou o mapa de áreas livres da bacia hidrográfica, conforme Figura 3. 


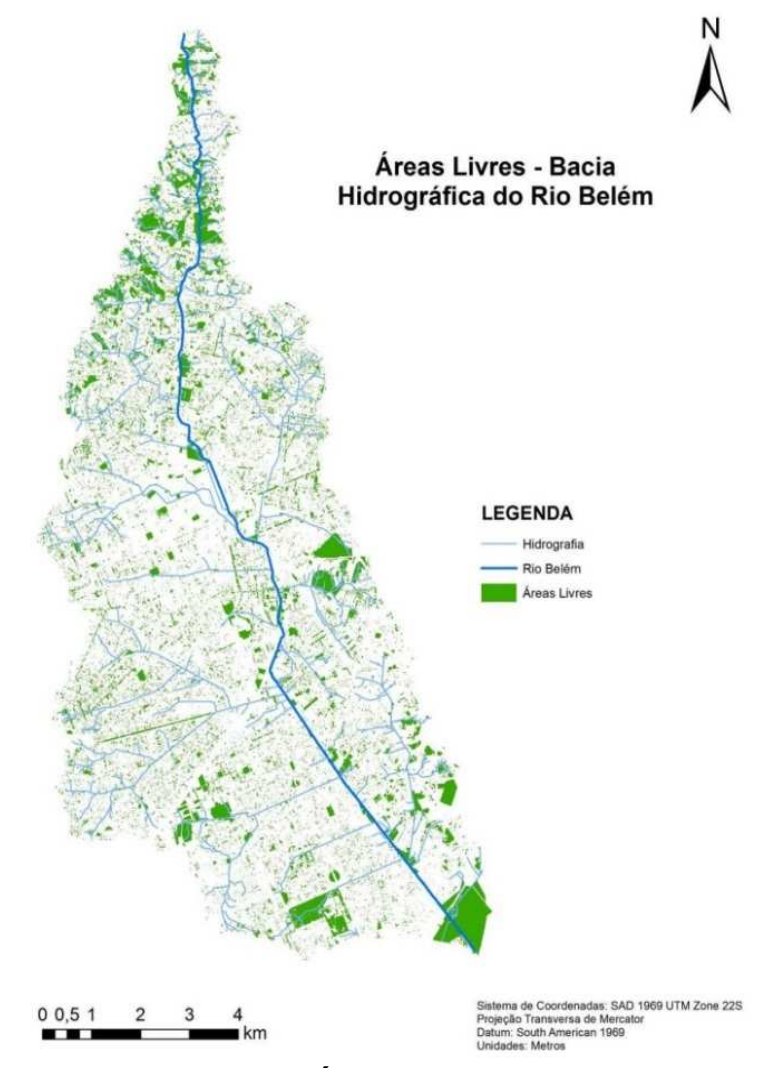

FIGURA 3 - Áreas livres da bacia hidrográfica do rio Belém.

Fonte: Adaptado de IPPUC, 2016.

Ao realizar uma análise mais detalhada do mapa gerado, pode-se concluir que aproximadamente $85 \%$ da área da bacia hidrográfica do Rio Belém é ocupada. A ocupação urbana implica em áreas impermeabilizadas que magnificam o escoamento superficial das águas. Isso acarreta em grandes vazões a serem drenadas pelo sistema de galerias, as quais muitas vezes, não suportam esse volume, culminando em inundações e alagamentos.

O resultado observado de $15 \%$ de áreas livres, ou não ocupadas, confirma a tendência, descrita por Góis \& Mendes (2013), de ocupação seguida de impermeabilização das áreas utilizadas para fixação da população. Deste modo, torna-se difícil a elaboração e aplicação de políticas públicas que priorizam técnicas que necessitam de áreas livres, pois vão na contramão da forma de estruturação das cidades. Em alguns casos, a própria população resiste às mudanças nas práticas correntemente utilizadas, apesar de estar sujeita às consequências negativas da aplicação de conceitos ultrapassados no planejamento e gestão da urbe.

A impermeabilização pode ser considerada uma vulnerabilidade local da bacia, pois é um dos fatores determinantes para a ocorrência de eventos críticos. $\mathrm{Na}$ região central da bacia, onde se vêem poucas áreas livres, é comum observar, em períodos de chuvas intensas, a formação de áreas alagadas. Isso ocorre devido ao sistema de drenagem ser antigo. Décadas atrás o sistema ainda suportava os volumes escoados, pois as áreas eram menos impermeabilizadas, favorecendo a infiltração, mas para os volumes atuais o sistema encontra-se subdimensionado. 
Ao observar o mapa de áreas livres gerado, também verifica-se a ausência das Áreas de Preservação Permanente ao longo dos rios. Na bacia predominam pequenos cursos d'água, com até 10 metros de largura, que exigem faixa de proteção de 30 metros a partir das margens (BRASIL, 2012). Mesmo com a ocupação da faixa, esta se mantém como Área de Preservação Permanente, mas pode ser legalmente utilizada desde que a atividade pretendida se enquadre nas categorias de utilidade pública, interesse social ou baixo impacto ambiental segundo as definições da Lei 12.651/12 (RAMOS \& AHMAD, 2016). Se existissem na bacia faixas preservadas ao longo dos rios estas poderiam funcionar como áreas de infiltração. Mesmo não havendo faixas contínuas preservadas, os fragmentos de áreas livres incidentes na faixa de proteção são considerados neste estudo, porque este uso se enquadraria como atividade de utilidade pública (como medida de redução de inundações) e de baixo impacto ambiental.

Ressalta-se que as áreas encontradas podem não ser as ideais para a implantação da técnica proposta, porém foram escolhidas para o estudo pela facilidade de uso, já que se encontram desocupadas e não são necessários esforços adicionais, como desapropriações e demolições, mas não há impedimento para que novas áreas sejam destinadas às medidas de baixo impacto por meio da utilização de instrumentos urbanísticos.

Com relação ao mapa de permeabilidade dos solos gerado (Figura 4), podese verificar que os solos presentes na porção norte da bacia hidrográfica apresentam alto e médio grau de permeabilidade. Já na região sul da bacia, observa-se a predominância de solos de média e baixa permeabilidade. Não é coincidência que ocorram inundações nessa região de forma mais acentuada, já que apresentam uma característica de saturação de água.

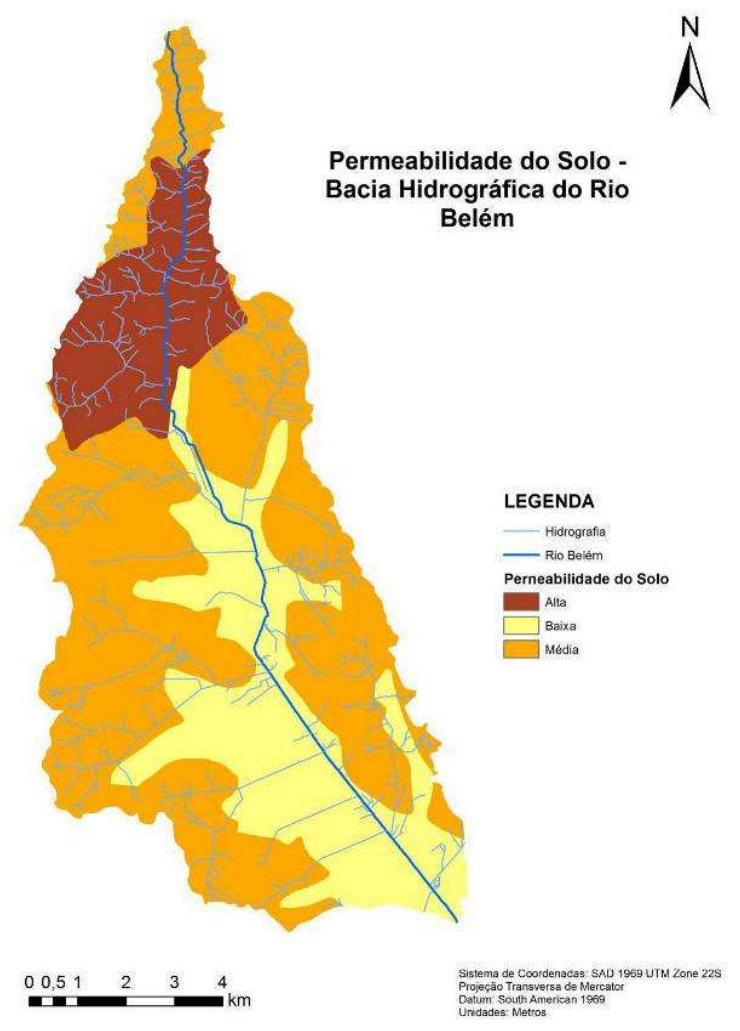

FIGURA 4 - Mapa de permeabilidade dos solos na bacia hidrográfica do rio Belém.

Fonte: Adaptado de IPPUC, 2016. 
Nessa área, os solos são originados por formações mais recentes em comparação com outros tipos de solos. Apresentam sedimentos inconsolidados, principalmente próximo às calhas dos afluentes e do próprio Rio Belém, carreados de locais mais altos da bacia e que ficam depositados na região mais plana da bacia hidrográfica. Assim, o assoreamento dos talvegues diminui a calha dos cursos d'água, fazendo com que a água extravase com maior facilidade e demandando mais ações de desassoreamento por parte do poder público, como realizado de forma periódica em alguns trechos da bacia. Ao considerar a implantação das técnicas analisadas, avalia-se a permeabilidade do solo como fator determinante para a implantação, principalmente para as medidas estudadas, pois baseiam-se no princípio da infiltração das águas no solo.

A Figura 5 apresenta as regiões com o lençol freático mais profundo com tons de azul escuro, principalmente localizados ao norte da bacia, com aproximadamente 13 metros abaixo do nível do solo. E em tons de azul mais claro, o lençol próximo à superfície, especialmente em áreas próximas às nascentes dos afluentes.

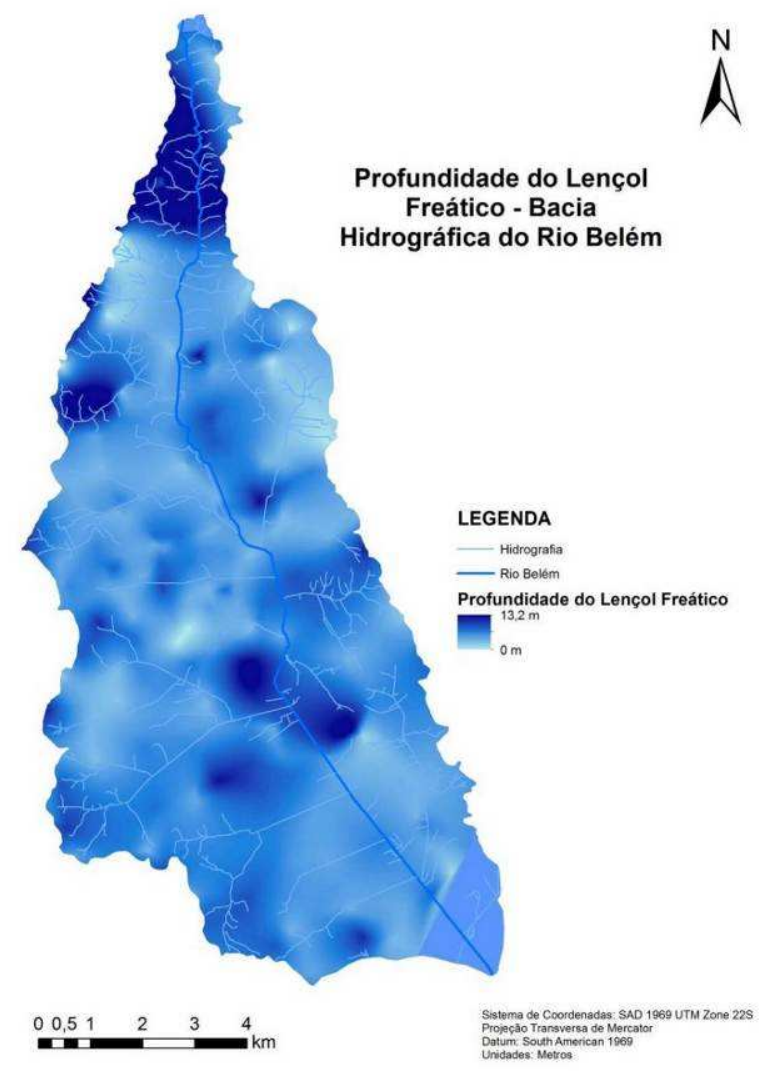

FIGURA 5 - profundidade do lençol freático na bacia hidrográfica do rio Belém.

Fonte: Adaptado de Instituto das Águas do Paraná, (2016).

Um dos motivos pelos quais as áreas ao entorno das nascentes são consideradas de Preservação Permanentes é justamente a profundidade mais baixa dos lençóis freáticos próximos a essas áreas. Como são regiões onde as águas subterrâneas praticamente se ligam às águas superficiais, existe maior possibilidade de contaminação.

A profundidade do lençol freático em relação à superfície pode dificultar a contaminação dos recursos hídricos subterrâneos, pois o solo funciona como um 
leito filtrante, purificando a água à medida que é infiltrada. Desta forma, quanto mais profundo o lençol freático, melhor a viabilidade de implantação das técnicas pesquisadas. As maiores declividades encontram-se principalmente próximas ao divisor de águas localizado ao norte da bacia hidrográfica, conforme a Figura 6.

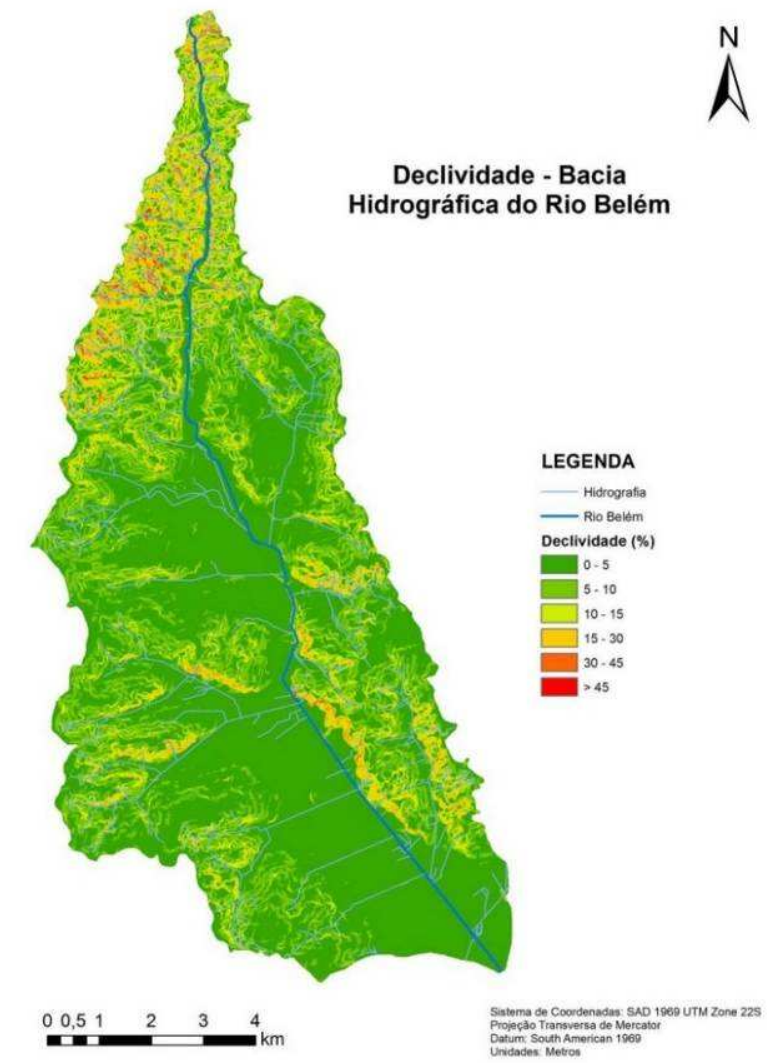

FIGURA 6 - Declividade da bacia hidrográfica do rio Belém.

Fonte: Adaptado de IPPUC, 2016.

Originalmente, para as técnicas de baixo impacto, a declividade do terreno não é um fator limitante para a implantação das técnicas estudadas. Porém, se a abordagem referente à velocidade do escoamento for considerada, essa variável pode ser avaliada como uma condicionante de projeto. As declividades são determinantes na velocidade do escoamento superficial.

A declividade também é fator que influência na microdrenagem da bacia. Além de conduzir os volumes de água escoados mais rapidamente até os corpos d'água, podem comprometer o sistema, caso as galerias convencionais não estejam preparadas para tais velocidades. Com base na metodologia criada, os mapas foram sobrepostos, utilizando o princípio da multiplicação entre os valores pontuados para cada restrição local. A pontuação dada a cada requisito pode ser vista no Quadro 4: 
QUADRO 4 - Valores dos Requisitos Reclassificados

\begin{tabular}{|c|c|c|}
\hline \multicolumn{2}{|c|}{ REQUISITOS } & VALORES ATRIBUÍDOS \\
\hline \multirow{2}{*}{ Áreas Livres } & Não é área livre & 0 \\
\cline { 2 - 3 } & É área livre & 1 \\
\hline \multirow{3}{*}{ Permeabilidade do Solo } & Baixa & 0 \\
\cline { 2 - 3 } & Média & 2 \\
\cline { 2 - 3 } & Alta & 1 \\
\hline Declividade & Apta & 0 \\
\hline Profundidade do Lençol & Abaixo de 0,6m & 1 \\
\cline { 2 - 3 } Freático & Acima de 0,6m & \\
\cline { 2 - 3 }
\end{tabular}

Observa-se que os valores iguais a zero dividem-se em áreas ocupadas (áreas livres igual a zero) e em áreas livres sem aptidão (zonas com solos de baixa permeabilidade ou regiões em que o lençol freático está acima de 0,6 m). Esses valores anulam o resultado da equação, o que torna essas áreas não aptas a receberem medidas de baixo impacto.

O resultado igual a 1 (um) indica uma aptidão média, pois representa que a área está livre e apresenta solo de média permeabilidade, declividade apta e o lençol freático abaixo de $0,6 \mathrm{~m}$ da superfície. Assim é possível a implantação das medidas, porém a média permeabilidade do solo necessita de elementos que auxiliem a infiltração, como por exemplo, a construção de drenos subterrâneos acoplados ao sistema.

O resultado igual a 2 (dois) diferencia-se do anterior por representar locais com solo com alta permeabilidade. Segundo as restrições expostas, esta seria a condição ideal para a implantação das técnicas pesquisadas. Esses resultados da multiplicação entre os requisitos são representados na Figura 7. No mapa pode se observar: as áreas ocupadas sem cor; áreas livres, porém sem condições de receber as medidas, em vermelho; áreas livres com média aptidão em amarelo; e áreas livres com alta aptidão em verde.

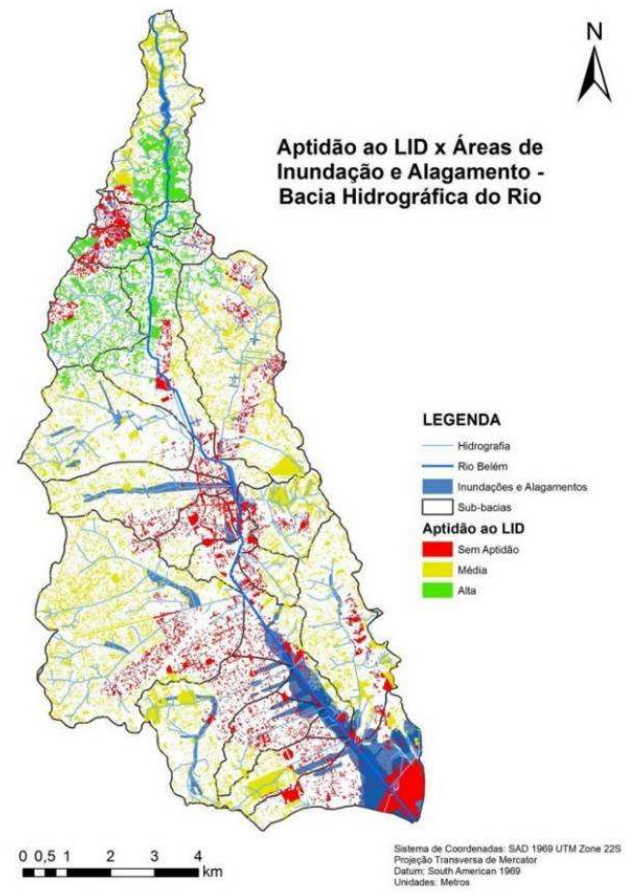

FIGURA 7 - Mapa de aptidão para as medidas de baixo impacto.

Fonte: Adaptado de IPPUC, 2016. 
Ao verificar quantas e quais são as áreas livres disponíveis para a aplicação das medidas estudadas, percebe-se a sua pequena parcela em relação à área total da bacia. Com a análise do mapa de aptidão gerado, junto com as condicionantes, verificou-se que apenas $15 \%$ da área total da bacia encontram-se livres para a aplicação das medidas. Destes, 34\% são regiões inaptas, $47 \%$ apresentam média aptidão e $19 \%$ das áreas livres são favoráveis à implantação. Grande parte da área possui densa ocupação urbana, a qual implica em áreas impermeabilizadas que aumentam o escoamento superficial das águas e, consequentemente, alteram o ciclo hidrológico. Em contrapartida são necessárias áreas que favoreçam a infiltração no solo, a fim de reestabelecer em parte o sistema natural.

O trecho norte da bacia hidrográfica do Rio Belém apresenta melhores condições de abrigar as medidas estudadas, visto que o fator determinante foi a permeabilidade do solo na região. As medidas de baixo impacto se baseiam no retardamento da chegada das águas à jusante. Portanto, as técnicas devem ser implantadas a montante dos locais que apresentam inundações e alagamentos de forma a amenizar o pico de vazão causado pelas precipitações.

Considerando o conjunto das análises realizadas e a geração do mapa de aptidão verificou-se que o trecho norte da bacia hidrográfica do Rio Belém apresenta melhores condições de abrigar as medidas estudadas. A maior parte da bacia possui média aptidão e a região próxima ao talvegue principal, a partir do seu curso médio, não é apta a implantação das medidas.

Verifica-se que as áreas aptas localizadas na porção norte da bacia principal são contidas por sete das 16 subbacias e estão inclusas em menor proporção em outras duas. Assim, é possível retardar a água escoada em todas essas por meio da aplicação direta das medidas estudadas.

A maior parte das nascentes das subbacias localiza-se em áreas de média aptidão. Essas áreas predominam até o curso médio de 12 delas. Considerando-se a implantação nessas circunstâncias, pode-se controlar o escoamento da maioria das subbacias pela implantação das medidas aliadas a obras que facilitem a infiltração.

A maior parte das áreas de baixa aptidão localiza-se próxima à foz do Rio Belém, o que inviabiliza a implantação em cinco das subbacias. Os alagamentos e inundações também podem ser observados do ponto de vista das subbacias. Os alagamentos, provocados pela ineficiência dos sistemas de drenagem convencionais, são potencializados na região central pela canalização de trechos de rios, onde as áreas alagáveis correspondem exatamente aos trechos canalizados. Para esses locais, a aplicação das medidas de baixo impacto a montante, na própria subbacia, colaboraria para a redução dos episódios mencionados.

Ao amenizar o pico de vazão nas subbacias também controla-se o volume de água que chega até a região sul da bacia, local com maior concentração de áreas suscetíveis às inundações. Verifica-se que a implantação das medidas de baixo impacto mostra-se mais viável a nível de subbacias do que ao analisar-se a bacia como um todo, embora sejam necessárias obras complementares de instalação de drenos na maioria das áreas.

Para este estudo, foram consideradas as condicionantes descritas no manual de implementação das medidas de baixo impacto (PRINCE GEORGE'S COUNTY, 1999). Porém para melhorar a análise realizada, além das condicionantes consideradas para as medidas de baixo impacto, outros indicadores também deveriam ser considerados. Como exemplo, cita os processos e regimes águas 
subterrâneas, que podem alterar o regime hídrico superficial e o modelo de elevação da bacia hidrográfica, pois a urbanização altera, com cortes e aterros, algumas declividades (MARTIN-MIKLE et al., 2015). Outro fator importante a ser considerado são as características climáticas dos locais escolhidos para a aplicação de tais técnicas e a sua capacidade de resposta frente às mudanças climáticas (AHIABLAM; ENGEL; CHAUBEY, 2012).

Por fim, deve-se considerar que a aplicação de determinada medida raramente se dará nas condições ideais, ou seja, com todos os fatores técnicos favoráveis reunidos na mesma área. Fatores não favoráveis podem dificultar ou até mesmo inviabilizar sua execução e devem ser considerados em escala local.

\section{CONCLUSÃO}

O objetivo de verificar a possibilidade de implantação das medidas de baixo impacto foi cumprido ao se constatar que parte da bacia hidrográfica do rio Belém apresenta condições técnicas de receber essas alternativas para drenagem urbana.

O modelo estruturado mostrou-se eficiente para a definição de locais próprios para receber as medidas de baixo impacto. Porém foram encontradas algumas dificuldades com relação aos dados utilizados no geoprocessamento. A despadronização entre dados de diferentes fontes, a ausência ou a falta de confiabilidade dos dados obtidos foram os principais problemas encontrados, principalmente com relação à profundidade do lençol freático, já que se trata de um dado que varia com a sazonalidade. Dados não confiáveis podem fazer que o resultado destoe da realidade.

Além das medidas estudadas, as quais priorizam a infiltração das águas no solo, é possível e recomenda-se o uso das demais medidas de baixo impacto, como os barris de chuva, as cisternas, telhados verdes e pisos permeáveis. Possuem relativa facilidade de instalação e não dependem de restrições locais como as outras técnicas abordadas.

Não se devem desconsiderar obras de maior porte, como a descanalização e a renaturalização do Rio Belém e seus afluentes, reconstituindo seus meandros, áreas de preservação permanente e planícies de inundação, para que tais áreas adquiram características semelhantes as naturais. Essas são opções que devem ser consideradas e estudadas, mesmo que por ora, pareçam inviáveis.

Por fim, sugerem-se estudos que continuem as discussões sobre a descanalização e a renaturalização dos rios urbanos, como a construção de modelos digitais que reconstituam o curso original desses corpos d'água, e pesquisas mais aprofundadas que relacionem a ocupação urbana aos riscos e vulnerabilidades a inundações e alagamentos.

\section{REFERÊNCIAS}

AHIABLAME, L.; ENGEL, B; CHAUBEY, I. Effectiveness of Low Impact Development Practices: Literature Review and Suggestions for Future Research. Water, Air \& Soil Pollution, v. 223, n. 7, p. 4253-4273, 2012. Disponível em : <http://link.springer.com/article/10.1007\%2Fs11270-012-1189-2>. Acesso em mai. 2016. doi:10.1007/s11270-012-1189-2 
BRASIL. Lei Federal n. 12.651, de 25 de maio de 2012. Diário Oficial da União. Brasília, 2012. Disponível em <http://www.planalto.gov.br/ccivil_03/_Ato20112014/2012/Lei/L12651.htm>. Acesso em mar. 2016.

GÓIS, J. S.; MENDES, L. E. Hidrologia e Hidrometria. In: TELLES, Dirceu D’Alkmin. Ciclo Ambiental da Água: da chuva à gestão. 2013. Ed. Edgar Blücher Ltda. São Paulo. 1a ed. 501 p.

INSTITUTO DAS ÁGUAS DO PARANÁ. Mapas e Dados Espaciais. 2016. Disponível em <http://www.aguasparana.pr.gov.br/modules/conteudo/conteudo.php?conteudo=79>. Acesso em mar. 2016.

IPPUC - INSTITUTO DE PESQUISA E PLANEJAMENTO URBANO DE CURITIBA. Banco de Dados - Mapas Temáticos. 2013. Disponível em <http://ippuc.org.br/geodownloads/geo.htm>. Acesso em mar. 2013.

MARTIN-MIKLE, C. J. et al. Identifying priority sites for low impact development (LID) in a mixed-use watershed. Landscape and Urban Planning, v. 140, p. 29-1, 2015. Disponível em: <http://www.sciencedirect.com/science/article/pii/ S016920461500078X>. Acesso em mai. 2016.

MELO, T. A. T. et al. Jardim de chuva: sistema de biorretenção para o manejo das águas pluviais urbanas. Ambiente Construído. Porto Alegre, v. 14, n. 4, p. 147-165, dez. $2014 . \quad$ Disponível em <http://www.scielo.br/scielo.php?script=sci_arttext\&pid=S1678-

$86212014000400011 \&$ Ing=pt\&nrm=iso >. Acesso em mai. 2016.

MIGUEZ, M.G.; VERÓL A.P.; REZENDE O.M. Drenagem Urbana: Do Projeto Tradicional à Sustentabilidade. 1. ed. Rio de Janeiro: Elsevier, 2015. 366.

PENNIMAN, D. C. et al. Capital Cost Comparisons between Low Impact Development (LID) and Conventional Stormwater Management Systems in Florida. Suburban Sustainability, v. 1, n. 2, 2013. Disponível em: <http://scholarcommons.usf.edu/subsust/vol1/iss2/1>. Acesso em mai. 2016. doi: http://dx.doi.org/10.5038/2164-0866.1.2.1.

PRINCE GEORGE'S COUNTY. Department of Environmental Resources. LowImpact Development Design Strategies: An Integrated Design Approach. Maryland, 1999. Disponível em: <ftp://lowimpactdevelopment.org/pub>. Acesso em mai. 2016.

RAMOS, R. I.; AHMAD, I. T. Código Florestal: Apreciação Atualizada. São Paulo: ABES-SP, ago. 2012. Disponível em: <http://www.abessp.org.br/arquivos/atualizacao_codigo_florestal.pdf >. Acesso em: mar. 2016.

TASSI, R. et al. Telhado verde: uma alternativa sustentável para a gestão das águas pluviais. Ambiente Construído. Porto Alegre, v. 14, n. 1, p. 139-154, Mar. 2014. 
Disponível em <http://www.scielo.br/scielo.php?script=sci_arttext\&pid=S1678$86212014000100012 \&$ Ing=en\&nrm=iso >. Acesso em mai. 2016.

TUCCI, C.E.M. Drenagem Urbana. Ciência e Cultura. v. 55 no. 4 São Paulo. 2003. 